Postprint version. Original publication in:

Basic and Applied Ecology (2006) 7:565-576

doi: http://dx.doi.org/10.1016/j.baae.2005.12.004

\title{
Multitrophic influences on egg distribution in a specialized leaf beetle at multiple spatial scales
}

\author{
Annette Heisswolf, Hans Joachim Poethke, Elisabeth Obermaier
}

Field Station Fabrikschleichach, University of Würzburg, Glashüttenstrasse 5, D-96181 Rauhenebrach

Summary. Egg distribution in herbivorous beetles can be affected by bottom-up (host plant), and by top-down factors (parasitoids and predators), as well as by other habitat parameters. The importance of bottom-up and top-down effects may change with spatial scale.

In this study, we investigated the influence of host plant factors and habitat structure on egg distribution in the leaf beetle Cassida canaliculata Laich. (Coleoptera: Chrysomelidae), a monophagous herbivore on Salvia pratensis L. (Lamiales: Lamiaceae), on four spatial scales: individual host plant, microhabitat, macrohabitat, and landscape. At the individual host plant scale we studied the correlation between egg clutch incidence and plant size and quality. On all other scales we analyzed the relationship between the egg clutch incidence of $C$. canaliculata and host plant percentage cover, host plant density, and the surrounding vegetation structure. Vegetation structure was examined as herbivores might escape egg parasitism by depositing their eggs on sites with vegetation factors unfavorable for host searching parasitoids.

The probability that egg clutches of $C$. canaliculata were present increased with an increasing size, percentage cover, and density of the host plant on three of the four spatial scales: individual host plant, microhabitat, and macrohabitat. There was no correlation between vegetation structure and egg clutch occurrence or parasitism on any spatial scale. A high percentage of egg clutches (38-56\%) was parasitized by Foersterella reptans Nees (Hymenoptera: Tetracampidae), the only egg parasitoid, but there was no relationship between egg parasitism and the spatial distribution of egg clutches of $C$. canaliculata on any of the spatial scales investigated. However, we also discuss results from a further study, which revealed top-down effects on the larval stage.

Zusammenfassung. Die Gelegeverteilung herbivorer Insekten kann sowohl durch bottom-up (Wirtspflanzen) und top-down Faktoren (Parasitoide und Prdatoren), als auch durch weitere Habitatparameter beeinflusst werden. Die Bedeutung der bottom-up und top-down Einflüsse kann zusätzlich von der räumlichen Skala abhängen.

In dieser Studie untersuchen wir den Einfluss von Wirtspflanzenfaktoren und der Vegetationsstruktur auf die Gelegeverteilung des Blattkäfers Cassida canaliculata Laich. (Coleoptera: Chrysomelidae), einem auf Salvia pratensis L. (Lamiales: Lamiaceae) monophagen Herbivoren, auf vier räumlichen Skalen: dem Wirtspflanzenindividuum, 


\begin{abstract}
Mikro- und Makrohabitat, sowie der Landschaft. Auf der Skala des Wirtspflanzenindividuums wurde der Zusammenhang zwischen der Gelegeinzidenz und der Größe und Qualität der Wirtspflanze untersucht. Auf allen anderen Skalen wurde die Korrelation zwischen der Gelegeinzidenz von $C$. canaliculata und der prozentualen Wirtspflanzendeckung und Wirtspflanzendichte, sowie der umgebenden Vegetationsstruktur analysiert. Die Vegetationsstruktur wurde untersucht, da die Herbivoren ihren Eiparasitoiden entkommen knönten, indem sie ihre Eigelege an Plätzen ablegen, deren Vegetationsstrukturparameter den Eiparasitoiden die Suche erschweren.

Die Wahrscheinlichkeit, dass Eigelege von C. canaliculata vorhanden waren, nahm mit zunehmender Größe, prozentualer Deckung und Dichte der Wirtspflanze auf drei der vier untersuchten Skalen zu: Wirtspflanzenindividuum, Mikrohabitat und Makrohabitat. Die Vegetationsstruktur stand jedoch auf keiner räumlichen Skala in einem Zusammenhang mit der Gelegeinzidenz bzw. der Parasitierung der Eigelege. Ein hoher Anteil der Eigelege (38-56\%) war durch den einzigen Eiparasitoiden Foersterella reptans Nees (Hymenoptera: Tetracampidae) parasitiert. Es konnte jedoch auf keiner der untersuchten räumlichen Skalen eine Korrelation zwischen der Parasitierung und der räumlichen Gelegeverteilung von $C$. canaliculata gefunden werden. Wir diskutieren aber auch Ergebnisse einer weiterführenden Studie, in der sich top-down Effekte auf das Larvalstadium zeigten.
\end{abstract}

Keywords. Cassida canaliculata, Chrysomelidae, egg parasitism, Foersterella reptans, herbivore, hostparasitoid interactions, plant quality, plant quantity, Salvia pratensis, tortoise beetle.

\title{
INTRODUCTION
}

Herbivorous insects are part of a complex multitrophic system in which the host plant as well as predators and parasitoids may affect reproductive success (Tscharntke et al., 2002; Vidal \& Tscharntke, 2001). On the one hand, egg distribution can be affected by the quality and quantity of the host plant (Mattson, 1980; Obermaier \& Zwölfer, 1999; Strong et al., 1984), since these are key factors for the development of herbivores. An oviposition preference for large, high-quality plants has been found in several herbivorous species (Craig et al., 1989; Kouki, 1993; Preszler \& Price, 1995). At larger spatial scales also host plant density can affect the egg distribution (Douwes, 1968; Root, 1973; Solomon, 1981).

On the other hand, it may also be important for successful offspring development to select oviposition sites protected from natural enemies (Hawkins et al., 1993; Hopkins \& Dixon, 1997; Price, 1988), i.e. "enemy-free space" (Jeffries \& Lawton, 1984). It has been reported that a complex plant architecture has a negative effect on the searching efficiency of parasitoids (Andow \& Prokrym, 1990; Gingras et al., 2002; Lukianchuk \& Smith, 1997; Romeis et al., 2005). Additionally, Obermaier et al. (2008) have shown that, in the tansy leaf beetle Galeruca tanaceti L. (Coleoptera: Chrysomelidae), high 
and dense vegetation close to the oviposition site had a negative effect on egg parasitism.

It has often been neglected in the past that the importance of factors which affect a system may change with spatial scale (Mohd Norowi et al., 1999, 2000; Ray \& Hastings, 1996; Wiens, 1989). This holds particularly for multitrophic systems, since herbivore and parasitoid may behave differently at different spatial scales. Cues used for host-finding change with spatial scale both in herbivores (Cronin \& Reeve, 2005; Moyes \& Raybould, 2001; Tscharntke \& Brandl, 2004) and parasitoids (Schmidt, 1991; Vinson, 1991). Until now, only few studies exist which have examined egg distribution in a multitrophic context across several spatial scales (e.g. Meiners \& Obermaier, 2004; Schwörer \& Völkl, 2001; Wilson \& Faeth, 2001). In this study, we investigated the relationship between both bottom-up (host plant) and top-down (parasitoids and predators) factors and the egg clutch incidence of the tortoise beetle Cassida canaliculata at four spatial scales: individual host plant, microhabitat, macrohabitat, and landscape. We investigated three hypotheses: The probability of oviposition should increase (1) with increasing plant quality and biomass, (2) with an increasing percentage cover and density of the host plant (bottom-up), and (3) on plants or sites less prone to egg-parasitism, i.e., supposedly, locations with high and dense vegetation structure (top-down).

\section{MATERIAL AND METHODS}

\section{Insects and plants}

Cassida canaliculata Laich. (Coleoptera: Chrysomelidae) is the largest German tortoise beetle (9-11 mm) (Trautner et al., 1989). It is monophagous on Salvia pratensis L. (Lamiales: Lamiaceae), the meadow sage, on which all developmental stages can be found. The eggs are deposited in small clutches of 4-12 eggs on the underside of the leaves and are covered with a secretion layer. Oviposition takes place from April to early June and each female produces 20-60 egg clutches. Larvae hatch after approximately 10 days and pupate 25-50 days later, depending on temperature. All larval stages feed on the undersides of the host plant leaves (A. Heisswolf, personal observations).

The host plant, S. pratensis, is a perennial herb with a ground rosette, which grows on dry meadows and field edges. The rosettes start to grow in late March and flowering begins in May (Schmeil \& Fitschen, 1996).

In the study area, egg clutches of $C$. canaliculata are parasitized by only one parasitoid, Foersterella reptans Nees (Hymenoptera: Tetracampidae). This species has also been described as a parasitoid of other Cassida species (Herting, 1973; Labeyrie, 
1962), but this is the first time it has been recorded from eggs of $C$. canaliculata (S. Vidal, personal communication).

\section{Study site}

The study was conducted in the nature reserve "Hohe Wann" in northern Bavaria $\left(50^{\circ}\right.$ $03^{\prime} \mathrm{N}, 10^{\circ} 35^{\prime} \mathrm{E}$ ), Germany. The size of the nature reserve is approximately 1000 ha. Thirty mesoxerophytic grassland sites on which $S$. pratensis occurred were chosen for investigation. Sites were selected in order to comprise a wide range of successional stages, from regularly managed open sites to sites almost overgrown by shrubs. The area of individual sites ranged from 1000 to $8000 \mathrm{~m}^{2}$.

\section{Investigated scales}

\section{Individual host plant scale}

The eggs are deposited on the host plant and the larvae stay on this plant until the late instars (A. Heisswolf, personal observation). Thus, the natal plant should at least support offspring survival until the larvae are large enough to be able to colonize another plant.

\section{Microhabitat scale}

This includes both the immediate surroundings $(r=0.15 \mathrm{~m})$ of the host plant as well as a larger circle $(r=1.0 \mathrm{~m})$ around the focal host plant. The vegetation structure around the host plant may be important, since at a close range the egg parasitoid presumably searches for its host by walking (Hilker \& Meiners, 1999; Romeis et al., 2005). Thus, dense and high vegetation might keep egg parasitoids - and possibly also other predators - from encountering the host plant. On the other hand, a high density and percentage cover of host plants in the surroundings of their natal host plant may increase survival chances of beetle larvae by facilitating colonization of another plant.

\section{Macrohabitat scale}

We investigated whether host plant density and vegetation structure of whole mesoxerophytic grassland sites affected parasitoid and beetle incidence. These features could be important for the long-term survival of beetle populations within a habitat, since a high host plant density could support a larger beetle population, which might lead to a lower risk of local extinction. 


\section{Landscape scale}

Here, we analyze landscape composition in five circles around the macrohabitats. This scale was included although there is hardly any knowledge on the dispersal behavior of $C$. canaliculata. We assume that the beetles do hardly ever fly and rather disperse by walking. We hypothesized that macrohabitats surrounded by higher amounts of suitable habitat should have a higher probability of beetle incidence, since they may be more easily reached by dispersing beetles and thus have a higher probability of recolonization.

\section{Investigated parameters}

\section{Individual host plant scale}

The distribution of egg clutches on individual host plants was analyzed on two mesoxerophytic grassland sites in early successional stages. Sampling took place from May 212002 to May 302002 (site 1) and from June 42002 to June 122002 (site 2). On each of the two sites 100 host plants were randomly chosen using a portable GPS. The following plant parameters were recorded: (1) maximum stalk height, (2) maximum rosette height, and (3) rosette diameter. On all plants the number of egg clutches was counted and all egg clutches were taken to the laboratory. Leaf nitrogen content and leaf water content were measured as surrogates of plant quality, because leaf nitrogen correlates with leaf protein content (Feeny, 1970; Long, 1961) and S. pratensis contains hardly any secondary plant compounds (Frohne \& Jensen, 1985). Three mature, non-senescent leaves of each plant were collected and oven-dried at $70^{\circ} \mathrm{C}$ for $48 \mathrm{~h}$. Leaf water content was measured as (fresh weight dry weight) / dry weight. Then, leaves of 50 plants per site (randomly selected from all studied plants) were ground in a mill (Retsch GmbH \& Co. KG, Haan, Germany), and analyzed for total leaf nitrogen content in an elemental CHN analyzer (WC Heraeus Elemental Analysis, Hanau, Germany).

\section{Microhabitat scale}

Several microhabitat characteristics were recorded within a radius of $0.15 \mathrm{~m}$ around the focal host plants used for the individual host plant scale: (1) percentage area covered by grasses, $S$. pratensis, other herbaceous plants, and the remaining open ground, and (2) the weighted mean vegetation height (following Gibson et al., 1987) . Additionally, host plant density and egg clutch density were recorded within a radius of $1.0 \mathrm{~m}$ around each focal host plant. Microhabitat parameters were recorded along with the individual host plant parameters. 


\begin{abstract}
Macrohabitat scale
Sampling on the 30 mesoxerophytic grassland sites took place at two time intervals and the sites were always sampled in a random order. From May 82002 to May 152002 egg clutch incidence was recorded on 30 randomly chosen host plants on each site. Additionally, six egg clutches (if available) were collected from each site for determination of parasitism. From June 132002 to June 272002 we recorded the vegetation structure as well as three general site features. General features were: (1) exposure in degrees, (2) inclination in three categories (slight, intermediate, and steep), and (3) the size of the site (derived from aerial photographs using the software package ArcView GIS 3.2, ESRI). For vegetation structure analysis $151 \mathrm{~m}^{2}$ plots were chosen randomly within each site. To accomplish this, a random number of steps was walked at random angles first from one edge of the site and then from each point to the next. Random numbers were obtained from a table. At each random point a square frame of $1 \mathrm{~m}^{2}$ was placed. Within this frame percent vegetation cover, percent cover by grass, herbaceous plants, the host plant $S$. pratensis, moss layer, shrub layer, and tree layer, the average height of the herbaceous layer, the shrub layer, and the tree layer were estimated. Also the number of host plants within each square was counted. The microclimate in each square was classified as (1) sunny, (2) shaded by shrubs or trees but still sunny, (3) shaded by shrubs, or (4) shaded by trees. This method was adopted from Meiners \& Obermaier (2004). From each plot, two host plants were randomly selected (i.e. 30 plants per site). For these plants maximum stalk height, maximum rosette height, and rosette diameter were recorded as for the individual host plant scale.
\end{abstract}

\title{
Landscape scale
}

On the landscape scale the surrounding vegetation structure of each of the 30 grassland sites was investigated for five radii $(100,200,300,400$, and $500 \mathrm{~m})$. Using the software package ArcView GIS 3.2 (ESRI), circles with the radii listed above were created around the centre of each site. From a biotope type map (J. Eibich, unpublished data) the percent area covered by each biotope type was calculated for each circle. For each radius the percent area covered by biotope types suitable for $\mathrm{S}$. pratensis was calculated. Figure 1 gives a schematic overview of the four spatial scales.

\section{Determination of parasitism}

The egg clutches collected were kept in the laboratory at room temperature in separate vials till hatching. Per plant parasitism was recorded as incidence, i.e. whether the focal egg clutch was parasitized or not. For individual sites, the overall rate of parasitism was calculated as the number of parasitized egg clutches divided by the number of egg 


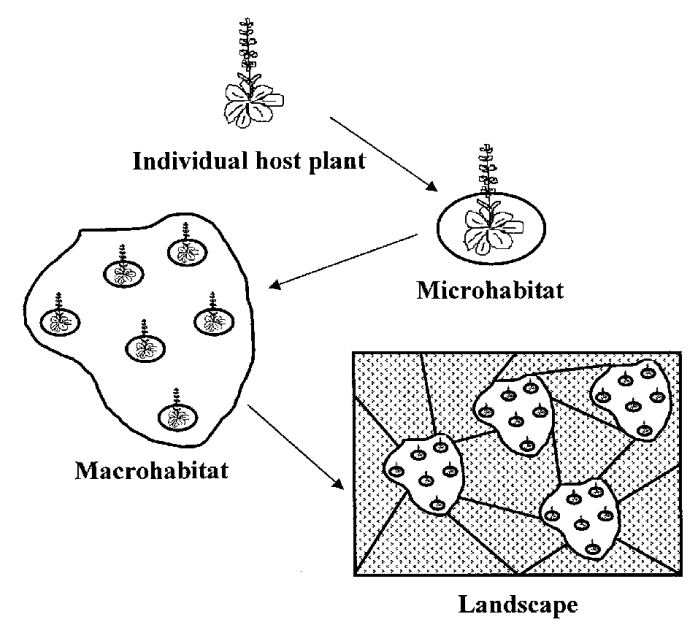

Figure 1: The four spatial scales on which the multitrophic interactions between $C$. canaliculata its host plant $S$. pratensis and its egg parasitoid $F$. reptans were studied. The dimensions of the four spatial scales are explained in the text.

clutches investigated per site. On the macrohabitat scale parasitism was recorded as incidence, i.e. whether any of the egg clutches collected on a site was parasitized or not.

As described above, sampling of egg clutches took place from mid-May to midJune, first on the 30 macrohabitats and then on the two grassland sites used for smallscale analyses. This method could cause a bias in the observed incidence of parasitism, because detailed information about the oviposition period of the egg parasitoid is lacking. Thus, there is a trade-off between collecting egg clutches too early (eggs not yet parasitized) and too late (parasitoids already emerged). However, it is known that leaf beetle egg clutches which are covered by a secretion layer are vulnerable to parasitism only for a short time (several days), because the egg cover hardens soon (reviewed by Gross, 1993; Hilker \& Meiners, 1999; and references therein). Thus, we decided to collect egg clutches in the middle of the species' oviposition period, when egg clutches of all ages should be present with an almost equal probability. This method should sufficiently minimize both the risk of over-sampling eggs which would be still suitable for parasitoid oviposition and eggs from which parasitoids already have emerged. We further tried to correct for the latter case by searching all egg clutches for emergenceholes of parasitoids. However, a reliable correction was not possible, since we also found several egg clutches from which parasitoids had emerged in the vials, but where no holes could be detected. 


\begin{abstract}
Statistics
Spearman correlation coefficients were calculated for all independent parameters within each spatial scale. Collinearity of variables was then eliminated by factor analysis. On the macrohabitat scale, a sine- and cosine-transformation was applied to the exposure values which ranged from $0^{\circ} / 360^{\circ}$ (north) to $180^{\circ}$ (south).

Logistic regressions were conducted for all spatial scales to analyze the effects of the investigated parameters on egg clutch or parasitoid incidence. In order to evaluate the goodness-of-fit of the regression models the coefficient of determination $R^{2}$ after Nagelkerke (1991) was considered $\left(R_{\text {Nagelkerke }}^{2}\right)$. To measure the classification accuracy of the models irrespective of threshold criteria, Receiver Operating Characteristics (ROC)-plots (Hanley \& McNeil, 1982, 1983) were analyzed. The area under the resulting plot (Area Under Curve $=$ AUC) provides a measure of the diagnostic accuracy of the model (Zweig \& Campbell, 1993). AUC values vary from 0.5 (determination by chance) to 1.0 (perfect classification) (Bonn \& Schröder, 2001; Zweig \& Campbell, 1993). For model validation on the individual host plant and microhabitat scale, models were calculated for each site separately and then externally validated with the data of the other site (Fleishman et al., 2003; Schröder \& Reineking, 2004). The success of the validation was measured using the AUC value (Reineking \& Schröder, 2004; Schröder, 2000).

The distributions of egg clutches were compared to a Poisson distribution using the Kolmogorov-Smirnov test. All procedures were calculated with the software packages SPSS 11.0 and 12.0.
\end{abstract}

\title{
RESULTS
}

\section{Individual host plant}

The mean number of egg clutches per plant was $1.5 \pm 0.2$ (site1) and $1.1 \pm 0.1$ (site 2). The maximum number of egg clutches per plant was seven (site 1) and three (site 2). On site 1 , the occurrence probability of $C$. canaliculata egg clutches on individual plants was positively correlated with the "average rosette diameter" $\left(R_{\text {Nagelkerke }}^{2}=\right.$ $\left.0.206, b=0.202, P_{\text {model }}<0.001, A U C=0.741, P_{A U C}<0.001, n=100\right)$. However, this model did not apply to site $2\left(A U C=0.492, P_{A U C}=n . s ., n=100\right)$. "Maximum rosette height", "maximum stalk height", and "leaf water content" were never significantly correlated with egg clutch incidence. The results for "leaf nitrogen content" were equivocal. On site 1 "leaf nitrogen content" was not correlated with egg clutch incidence, but was positively correlated with the "average rosette diameter" $\left(r_{s}=0.316, P=0.025, n=50\right)$. On site 2 "leaf nitrogen content" itself was nega- 
tively correlated with egg clutch incidence $\left(R_{\text {Nagelkerke }}^{2}=0.142, b=-2.624, P_{\text {model }}=\right.$ $0.019, A U C=0.684, P_{A U C}=0.030, n=50$ ), but was not significantly correlated with the "average rosette diameter" $\left(r_{s}=-0.126, P=n . s ., n=50\right)$.

The number of egg clutches per plant was randomly distributed, i.e. the distribution did not differ significantly from a Poisson distribution (site 1: $Z=0.232, P=n . s$.; site $2: Z=0.586, P=n . s$.$) . On site 1$ and $2,56 \%$ and $38 \%$, respectively, of all collected egg clutches were parasitized. The probability of egg parasitism increased with the "number of egg clutches per host plant" on site $1\left(R_{\text {Nagelkerke }}^{2}=0.173, b=1.486, P_{\text {model }}=\right.$ $0.010, A U C=0.654, P_{A U C}=n . s ., n=49$ ), but the model accuracy (i.e. the AUC value) was poor and not significant and the model was not supported by the results from site $2\left(A U C=0.595, P_{A U C}=n . s ., n=47\right)$. The probability of parasitism was not correlated with the "average rosette diameter" of the host plants.

\section{Microhabitat}

On the microhabitat scale we analyzed the vegetation structure around the host plant individuals examined above. The occurrence probability of an egg clutch on the focal host plant was best explained by the "percentage cover of host plants" within a radius of $0.15 \mathrm{~m}$ around this plant on site $1\left(R_{\text {Nagelkerke }}^{2}=0.297, b=0.080, P_{\text {model }}<\right.$ $0.001, A U C=0.782, P_{A U C}<0.001, n=100$, Figure 2). This model also applied to site $2\left(A U C=0.623, P_{A U C}=0.035, n=100\right)$. On site 2 , the occurrence probability of an egg clutch could also be explained by the "host plant density" within a radius of 1 $\mathrm{m}$ around the focal host plant $\left(R_{\text {Nagelkerke }}^{2}=0.064, b=0.077, P_{\text {model }}=0.027, A U C=\right.$ $\left.0.627, P_{A U C}=0.029, n=100\right)$. "Percent cover by host plants" and "host plant density" were positively correlated for site $2\left(r_{s}=0.268, P=0.007, n=100\right)$, but not for site $1\left(r_{s}=0.045, P=n . s ., n=100\right)$.

The complexity of the vegetation structure (i.e. percentage vegetation cover and weighted mean vegetation height) in the surroundings of the focal host plant was not correlated with the egg clutch incidence of $C$. canaliculata in any of the study sites. Likewise, there was no relationship between the probability of parasitism of the focal egg clutch and the complexity of the vegetation structure. Parasitism increased, however, with an increasing "density of egg clutches" within a radius of $1 \mathrm{~m}$ on site 1 $\left(R_{\text {Nagelkerke }}^{2}=0.133, b=0.157, P_{\text {model }}=0.025, A U C=0.675, P_{A U C}=0.040, n=49\right.$, Figure 3), but the test for site 2 was not significant $\left(A U C=0.579, P_{A U C}=n . s ., n=\right.$ 47). The distribution of egg clutches within this radius was - on both study sites found to be clumped, i.e. it differed significantly from a Poisson distribution (site 1: $Z=3.765, P<0.001$; site $2: Z=1.509, P=0.021)$. Densities of egg clutches and host plants were positively correlated on both study sites (site 1: $r_{s}=0.879, P<0.001, n=$ 100; site 2: $r_{s}=0.393, P<0.001, n=100$ ). 


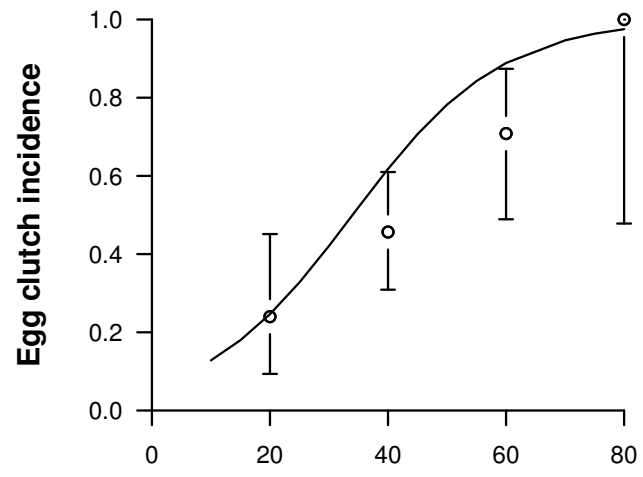

Cover by host plants (\%)

Figure 2: Relationship between the percentage area covered by host plants within a radius of $0.15 \mathrm{~m}$ around a focal host plant and the probability of oviposition of $C$. canaliculata on this plant on site 1 (microhabitat scale). Circles and bars: mean $\pm 95 \%$ CI for four classes of host plant cover; line: logistic regression; $n=100$ microhabitats.

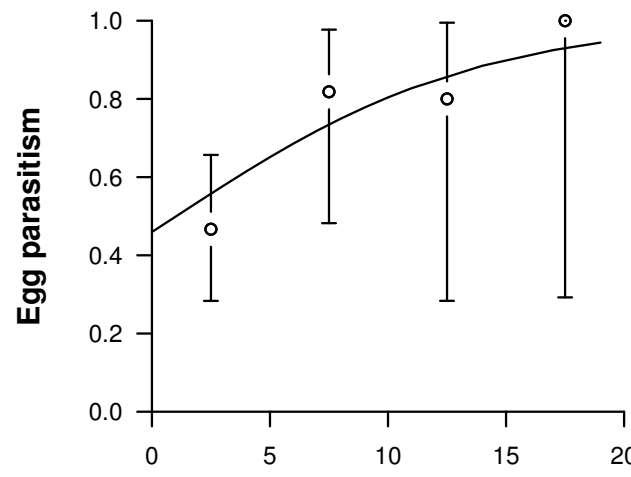

Egg clutch number $(r=1 \mathrm{~m})$

Figure 3: Relationship between the egg clutch number within a radius of $1 \mathrm{~m}$ around a focal host plant with an egg clutch of $C$. canaliculata and the probability of this egg clutch being parasitized by $F$. reptans on site 1 (microhabitat scale). Circles and bars: mean $\pm 95 \% \mathrm{CI}$ for four classes of egg clutch numbers; line: logistic regression; $n=49$ microhabitats. 


\section{Macrohabitat}

Egg clutches of $C$. canaliculata were found on $50 \%$ of the investigated sites. There were two factors that were significantly correlated with the incidence of $C$. canaliculata egg clutches at this spatial scale. The first factor, "host plant cover and density", was extracted from the parameters "host plant cover" and "host plant density" by factor analysis: The higher the percentage cover and density of the host plant, S. pratensis, the higher the probability of egg clutch incidence on a site $\left(R_{\text {Nagelkerke }}^{2}=0.338, b=\right.$ $1.283, P_{\text {model }}=0.003, A U C=0.795, P_{A U C}=0.006, n=30$ ). However, in contrast to the individual host plant scale, the mean "rosette diameter" per site was not correlated with the incidence of $C$. canaliculata egg clutches at this spatial scale.

The second important factor, "complexity of the vegetation", was extracted from the parameters "percent cover of shrubs", "percent cover of trees", "average height of the shrub layer", and "average height of the tree layer". These factors describe the spectrum of successional stages from areas regularly mown to sites which have been abandoned for several years and are mostly overgrown by shrubs: The lower the "complexity of the vegetation" of a site the higher the probability of oviposition of $C$. canaliculata $\left(R_{\text {Nagelkerke }}^{2}=0.354, b=-1.539, P_{\text {model }}=0.002, A U C=0.763, P_{A U C}=\right.$ $0.014, n=30$ ). The factors "host plant cover and density" and "complexity of the vegetation" were negatively correlated $\left(r_{s}=-0.365, P=0.047, n=30\right)$. A model containing both factors explained $46.8 \%$ of the total variance in egg clutch incidence $\left(R_{\text {Nagelkerke }}^{2}=0.468, P_{\text {model }}=0.002, A U C=0.853, P_{A U C}=0.001, n=30\right)$, i.e. $13 \%$ more than already explained by the univariate model which used only "host plant cover and density". However, the change in explained variance caused by the factor "complexity of the vegetation" was only marginally significant $(P=0.044)$.

Additionally, the parameter "microclimate" (categorical) was correlated both with the factors "host plant cover and density" $\left(r_{s}=0.473, P=0.008, n=30\right)$ and "complexity of the vegetation" $\left(r_{s}=-0.823, P<0.001, n=30\right)$ and was thus not included in the statistical models. Sites with high host plant cover and density and less complex vegetation structure had a sunnier microclimate. The "exposure (cosine-transformed)" of a site also explained some variance in egg clutch incidence and could be used as an additional parameter in both statistical models presented above (it was not correlated to the factors used in these models). The beetles preferred sites with a southern exposure. The size of the site was not correlated with the occurrence of $C$. canaliculata egg clutches.

Parasitized egg clutches were found on 11 of the 15 sites with oviposition incidences of $C$. canaliculata. There was no relationship between the "complexity of the vegetation" and the probability of parasitism. Likewise, parasitism was not density dependent on this scale. 


\section{Landscape}

A landscape level analysis of the surroundings of the 30 sites within five radii of $100500 \mathrm{~m}$ revealed no effects of the heterogeneity of biotope types or the proportion of suitable habitat on the probability of oviposition of $C$. canaliculata. Parasitism was not studied at this spatial scale.

\section{DISCUSSION}

The egg distribution of an herbivorous beetle can be influenced by both bottom-up and top-down factors. The results of this study indicate that within the tritrophic system of the herbivore $C$. canaliculata, its host plant $S$. pratensis, and its egg parasitoid $F$. reptans, the egg distribution of the herbivore was predominantly affected by bottom-up factors. Over three spatial scales (host plant, microhabitat, and macrohabitat) the occurrence probability of egg clutches increased with increasing size, cover and density of the host plant. However, on the individual host plant scale, results were inconsistent for the two study sites, which stresses the importance of spatial model validation. Parasitism by $F$. reptans was high (site 1: 56\%; site 2: 38\%). Yet, there seemed to be no relationship between egg parasitism and the egg clutch incidence of $C$. canaliculata at any of the spatial scales investigated. An overview of the most relevant parameters is given in Table 1.

\section{Bottom-up effects}

At the scale of the single host plant, there was a positive relationship between oviposition by $C$. canaliculata and the rosette diameter on site 1 . This parameter may represent a good indicator of the leaf biomass available to the larvae and was on site 1 also related to plant quality, i.e. to leaf nitrogen content. As to plant quality, Crawley (1989) and White (1993) argue that nitrogen is the limiting nutrient which is most important for herbivore growth. Indeed, development time of $C$. canaliculata larvae was shorter on leaves with high nitrogen content (Heisswolf et al., 2005). On site 2, however, leaf nitrogen content was not significantly correlated to host plant size and did even correlate negatively with egg clutch occurrence. Also, egg clutch incidence was not correlated with host plant size. One possible explanation for this result is that constraints like time- or egg-limitation may have prevented females from choosing oviposition sites based on host plant quality. It could also be hypothesized that the fact that site 2 was sampled 2 weeks after site 1 could have led to these ambiguous results for the two study sites. However, it would seem quite unlikely that this difference in sampling time could account for the different results on the two sites, because the mean leaf nitrogen content differed only marginally $(<0.1 \%)$ between the two study 


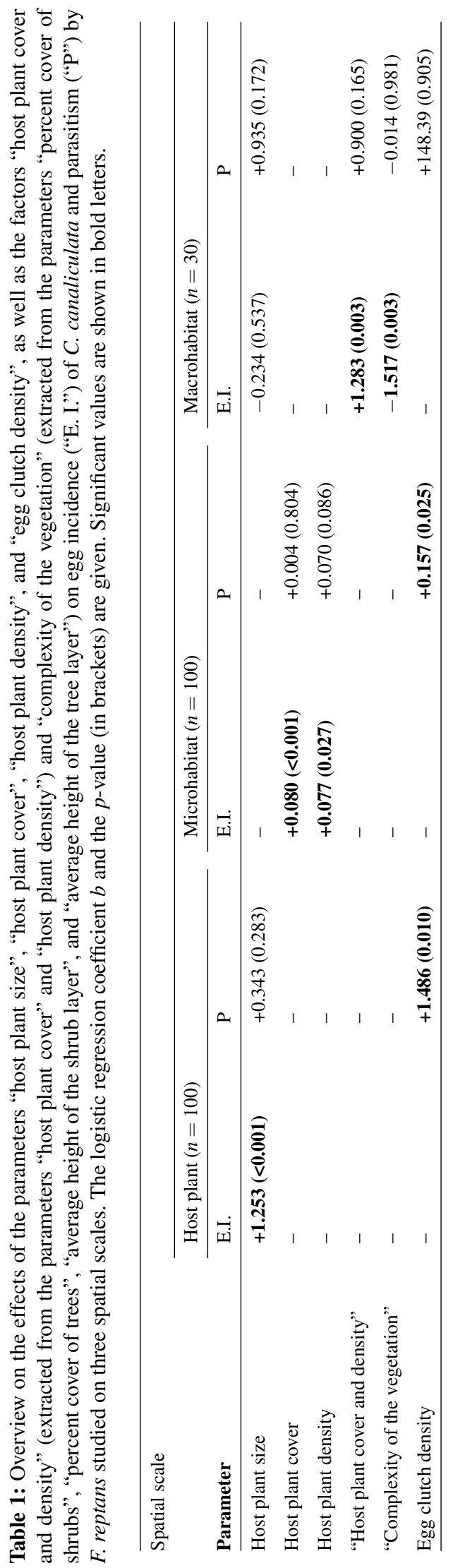


sites. Only controlled oviposition choice experiments with high- and low-quality plants could finally elucidate this issue.

On the micro- and macrohabitat scale, egg clutch incidence correlated positively with host plant cover and density. Since both adults and larvae exclusively feed on S. pratensis, the importance of the host plant as a food resource is evident. However, the reasons for a positive correlation between host plant cover and density and the occurrence of egg clutches within a micro- and a macrohabitat may be quite different. On the microhabitat scale, large host plants as well as patches of high host plant density may be more easily detected by females of $C$. canaliculata (Douwes, 1968; Solomon, 1981). Moreover, a female may stay longer once she has found a large plant or a dense patch as predicted by the "resource concentration hypothesis" (Root, 1973). This would also explain the clumped distribution of egg clutches on the microhabitat scale. On the macrohabitat scale, host plant cover and density may represent a good measure of habitat quality. Classical metapopulation studies consider size and isolation of a site as determinants of the occupancy of a site. Thomas et al. (2001) hypothesize, however, that the quality of a site is more important for the persistence of a population. Like in the present study, site area and occurrence were not correlated in any of the species studied by Thomas et al. (2001), rather the correlation between habitat quality and species occurrence was highly significant.

On the landscape scale, the probability of oviposition in a focal site was expected to increase with the proportion of suitable habitat in the surroundings. Also, the heterogeneity of vegetation types surrounding a site could have an effect on the diversity of species and thus on the occurrence probability of a species in a focal site (Kruess \& Tscharntke, 1994, 2000; Steffan-Dewenter et al., 2002). Yet, neither of the two parameters was correlated to the presence of beetle eggs in any site. Since little is known about the ecology of $C$. canaliculata, it may be possible that the spatial scales chosen in this study did not match the dispersal abilities of the beetle (Chust et al., 2003; With \& Crist, 1995). Moreover, there may be landscape parameters that affect the beetle but which were not examined in this study (cf. Saunders et al., 1991).

\section{Top-down effects}

Host plant factors seem to influence the egg distribution of $C$. canaliculata, but it may additionally be shaped by the higher trophic level (Tscharntke et al., 2002; Vidal $\&$ Tscharntke, 2001). Top-down effects can be imposed by both predators and parasitoids. In a preliminary study (A. Heisswolf, unpublished data), removal of eggs or egg clutches by predators could be observed only in very few cases $(<2 \%$ of 235 egg clutches). Thus, egg removal by predators does not seem to be important in C. canaliculata. There may be predators which suck eggs and also many parasitoids have been 
reported to feed on their hosts' eggs (e.g. Meiners et al., 1997). However, both these mortality factors cannot be easily detected. Foersterella reptans is the only parasitoid of $C$. canaliculata eggs in the study area. In the present study we therefore focused on $F$. reptans as the main top-down effect during the host's egg stage. However, no direct or indirect (via structural complexity) influence of this egg parasitoid on the distribution of egg clutches of $C$. canaliculata could be shown at any of the spatial scales investigated.

Egg parasitism on site 1 was positively density dependent on the microhabitat scale. This result could, however, not be validated for site 2 , which may be due to the fact, that the two sites were sampled one after the other. Since the beetle eggs were not evenly distributed but clumped, one might assume that the beetles are not adapted to the selection pressure imposed by positively density dependent parasitism. However, analyzing egg distribution in the presence of parasitism gives no information about the optimal distribution without parasitoids. This distribution could be even more aggregated. For example, a clumped egg distribution could provide a "selfish herd effect" (Hamilton, 1971) if larvae have a higher chance of survival not only in groups on a plant but also in a patch with high larval densities on other host plants in the surrounding. As a consequence, larval mortality due to predation and parasitism will influence the female beetles' fitness and might shape their oviposition behavior.

On the microhabitat scale, the vegetation structure did neither affect oviposition of $C$. canaliculata nor egg parasitism by $F$. reptans. This contradicts the hypothesis that a complex vegetation structure provides a reduced risk of parasitism and that beetles should prefer to oviposit on host plants growing in dense vegetation (Andow \& Prokrym, 1990; Gingras et al., 2002; Lukianchuk \& Smith, 1997; Romeis et al., 2005). A reason for the findings of the present study may be that parasitoids of monophagous herbivores may be better adapted to olfactory or visual cues emitted by the host plant (Dicke, 2000; Dicke \& van Loon, 2000; Dicke et al., 2003; Vinson, 1976). In this case, dense vegetation may not greatly affect the host plant detection ability of parasitoids. However, as discussed above, larval mortality might also shape the oviposition decision of female beetles. Correspondingly, we could show in a predator-exclusion study that survival of $C$. canaliculata larvae was higher on large host plants, probably due to an enemy-free space caused by the more complex plant architecture of large plant individuals (Heisswolf et al., 2005).

On the macrohabitat scale, grassland habitats in an early successional stage with little shrub cover had a higher probability to be used for oviposition than later stages with a higher structural complexity of the vegetation. Egg parasitism by F. reptans, however, was not correlated to vegetation structure. This and similar results by Meiners \& Obermaier (2004) stand in contradiction to the hypothesis of an indirect higher 
trophic level effect. Yet, host plant cover/density and structural complexity were negatively correlated. The higher the structural complexity of the site the lower was the host plant cover and density. Since host plant effects were shown to be important on two smaller scales and the probability of parasitism was not affected by the vegetation structure, no evidence of an indirect higher trophic level effect via the vegetation structure could be shown on the macrohabitat scale. There are other possible explanations for the higher probability of beetle occurrence on sites with a less complex vegetation structure: Since temperature is a crucial factor for the development of larvae (Jackson \& Elliott, 1988; King et al., 1985; Stiefel et al., 1997), a site with a high proportion of shading shrubs may not be suitable for successful development of larvae. This explanation is also supported by the result that beetle eggs were found more often on south exposed sites with a sunny microclimate. Moreover, sites with little shrub cover may be more easily colonized by the beetles.

In summary, our study indicates a positive influence of host plant size, cover, and density, (i.e. of bottom-up effects) on the probability of finding egg clutches of $C$. canaliculata on three of the four spatial scales investigated. This consistency over the whole range of spatial scales is a quite extraordinary result. It may be explained by the fact that $C$. canaliculata is a monophagous herbivore. Although a high percentage of egg clutches was parasitized by $F$. reptans, we could show no relationship between egg distribution and egg parasitism. Based on the results of this study, a complex vegetation structure does not seem to offer enemy-free space for the beetle's eggs. Future manipulative experiments will be needed to test hypotheses about possible ecological processes explaining the observed patterns.

\section{ACKNOWLEDGEMENTS}

We thank Stefan Vidal for identification of the egg parasitoids and Elfriede Reisberg for nitrogen analyses. We are grateful to Thomas Hovestadt, Erhard Strohm, Thomas Hoffmeister and an anonymous referee for contributing valuable comments on earlier versions of this manuscript. The authors thank the government of Lower Franconia for permission to work in the nature reserve. 


\section{REFERENCES}

Andow, D. A. \& Prokrym, D. R. (1990). Plant structural complexity and host-finding by a parasitoid. Oecologia 82: 162-165. 2, 15

Bonn, A. \& Schröder, B. (2001). Habitat models and their transfer for single and multi species groups: a case study of carabids in an alluvial forest. Ecography 24: 483-496. 8

Chust, G., Pretus, J. L., Ducrot, D., Bedós, A. \& Deharveng, L. (2003). Identification of landscape units from an insect perspective. Ecography 26: 257-268. 14

Craig, T. P., Itami, J. K. \& Price, P. W. (1989). A strong relationship between oviposition preference and larval performance in a shoot-galling sawfly. Ecology 70: 1691-1699. 2

Crawley, M. J. (1989). Insect herbivores and plant population dynamics. Annual Review of Entomology 34: 531-564. 12

Cronin, J. T. \& Reeve, J. D. (2005). Host-parasitoid spatial ecology: a plea for a landscape-level synthesis. Proceedings of the Royal Society B: Biological Sciences 272: 2225-2235. 3

Dicke, M. (2000). Chemical ecology of host-plant selection by herbivorous arthropods: a multitrophic perspective. Biochemical Systematics and Ecology 28: 601-617. 15

Dicke, M., van, R. M. P. P. \& de Boer, J. G. (2003). Inducible indirect defence of plants: from mechanisms to ecological functions. Basic and Applied Ecology 4: 27-42. 15

Dicke, M. \& van Loon, J. J. A. (2000). Multitrophic effects of herbivore-induced plant volatiles in an evolutionary context. Entomologia Experimentalis et Applicata 97: 237-249. 15

Douwes, P. (1968). Host selection and host finding in the egg-laying female Cidaria albulata L. (Lepidoptera: Geometridae). Opuscula Entomologica 33: 233-379. 2, 14

Feeny, P. (1970). Seasonal changes in oak leaf tannins and nutrients as a cause of spring feeding by winter moth caterpillars. Ecology 51: 565-581. 5

Fleishman, E., Nally, R. M. \& Fay, J. P. (2003). Validation tests of predictive models of butterfly occurrence based on environmental variables. Conservation Biology 17: 806-817. 8

Frohne, D. \& Jensen, U. (1985). Systematik des Planzenreichs (unter besonderer Berücksichtigung chemischer Merkmale und pflanzlicher Drogen). Fischer, Stuttgart. 5

Gibson, C. W. D., Dawkins, H. C., Brown, V. \& Jepsen, M. (1987). Spring grazing by sheep: effects of seasonal changes during early old field succession. Vegetatio 70: $33-43.5$

Gingras, D., Dutilleul, P. \& Boivin, G. (2002). Modeling the impact of plant structure on host-finding behavior of parasitoids. Oecologia 130: 396-402. 2, 15

Gross, P. (1993). Insect behavioral and morphological defenses against parasitoids. Annual Review of Entomology 38: 251-273. 7

Hamilton, W. D. (1971). Geometry for the selfish herd. Journal of Theoretical Biology 31: 295-311. 15

Hanley, J. A. \& McNeil, B. J. (1982). The meaning and use of the area under a receiver operating characteristic (ROC) curve. Radiology 143: 29-36. 8

Hanley, J. A. \& McNeil, B. J. (1983). A method of comparing the areas under receiver operating characteristic curves derived from the same cases. Radiology 148: 839-843. 8 
Hawkins, B. A., Thomas, M. B. \& Hochberg, M. E. (1993). Refuge theory and biological control. Science 262: 14291432. 2

Heisswolf, A., Obermaier, E. \& Poethke, H. J. (2005). Selection of large host plants for oviposition by a monophagous leaf beetle: nutritional quality or enemy-free space? Ecological Entomology 30: 299-306. 12, 15

Herting, B. (1973). A Catalogue of Parasites and Predators of Terrestrial Arthropods. Section A. Host or Prey/Enemy 3. Commonwealth Agricultural Bureaux, Institute of Biological Control. 3

Hilker, M. \& Meiners, T. (1999). Chemical cues mediating interactions between chrysomelids and parasitoids. In: Cox, M. L. (ed.) Advances in Chrysomelidae Biology, vol. 1, Backhuys Publishers, Leiden, pp. 197-216. 4, 7

Hopkins, G. W. \& Dixon, A. F. G. (1997). Enemy-free space and the feeding niche of an aphid. Ecological Entomology 22: $271-274.2$

Jackson, J. J. \& Elliott, N. C. (1988). Temperature-dependent development of immature stages of the western corn rootworm, Diabrotica virgifera virgifera (Coleoptera: Chrysomelidae). Environmental Entomology 17: 166-171. 16

Jeffries, M. J. \& Lawton, J. H. (1984). Enemy free space and the structure of ecological communities. Biological Journal of the Linnean Society 23: 269-286. 2

King, J. E., Price, R. G., Young, J. H., Wilson, L. J. \& Pinkston, K. N. (1985). Influences of temperature on development and survival of the immature stages of the elm leaf beetle, Pyrrhalta luteola (Müller) (Coleoptera: Chrysomelidae). Environmental Entomology 14: 272-274. 16

Kouki, J. (1993). Female's preference for oviposition site and larval performance in the water lily beetle, Galerucella nymphaeae (Coleoptera: Chrysomelidae). Oecologia 93: 42-47. 2

Kruess, A. \& Tscharntke, T. (1994). Habitat fragmentation, species loss, and biological control. Science 264: 15811584. 14

Kruess, A. \& Tscharntke, T. (2000). Species richness and parasitism in a fragmented landscape: experiments and field studies with insects on Vicia sepium. Oecologia 122: 129-137. 14

Labeyrie, V. (1962). Influence des parasites oophages sur la régulation des populations de Cassida deflorata Suff. Entomophaga 6: 257-263. 3

Long, C. (ed.) (1961). Biochemists' handbook. Van Nostrand, Princeton. 5

Lukianchuk, J. L. \& Smith, S. M. (1997). Influence of plant structural complexity on the foraging success of Trichogramma minutum: a comparison of search on artificial and foliage models. Entomologia Experimentalis et Applicata 84: 221-228. 2, 15

Mattson, W. J. (1980). Herbivory in relation to plant nitrogen content. Annual Review of Ecology and Systematics 11: 119-161. 2

Meiners, T., Köpf, A., Stein, C. \& Hilker, M. (1997). Chemical signals mediating interactions between Galeruca tanaceti L. (Coleoptera, Chrysomelidae) and its egg parasitoid Oomyzus galerucivorus (Hedqvits) (Hymenoptera, Eulophidae). Journal of Insect Behavior 10: 523-539. 15

Meiners, T. \& Obermaier, E. (2004). Hide and seek on two spatial scales - vegetation structure affects herbivore oviposition and egg parasitism. Basic and Applied Ecology 5: 87-94. 3, 6, 15

Mohd Norowi, H., Perry, J. N., Powell, W. \& Rennolls, K. (1999). The effect of spatial scale on interactions between two weevils and their food plant. Acta Oecologica 20: 537-549. 3

Mohd Norowi, H., Perry, J. N., Powell, W. \& Rennolls, K. (2000). The effect of spatial scale on interactions between two weevils and their parasitoid. Ecological Entomology 25: 188-196. 3 
Moyes, C. L. \& Raybould, A. F. (2001). The role of spatial scale and intraspecific variation in secondary chemistry in host-plant location by Ceutorhynchus assimilis (Coleoptera: Curculionidae). Proceedings of the Royal Society B: Biological Sciences 268: 1567-1573. 3

Nagelkerke, N. J. D. (1991). A note on the general definition of the coefficient of determination. Biometrika 78: 691-692. 8

Obermaier, E., Heisswolf, A., Poethke, H. J., Randlkofer, B. \& Meiners, T. (2008). Plant architecture and vegetation structure: two ways for insect herbivores to escape parasitism. European Journal of Entomology 105: 233-240. 2

Obermaier, E. \& Zwölfer, H. (1999). Plant quality or quantity? Host exploitation strategies in three Chrysomelidae species associated with Asteraceae host plants. Entomologia Experimentalis et Applicata 92: 165-177. 2

Preszler, R. W. \& Price, P. W. (1995). A test of plant-vigor, plant-stress, and plant-genotype effects on leaf-miner oviposition and performance. Oikos 74: 485-492. 2

Price, P. W. (1988). Inversely density-dependent parasitism: the role of plant refuges for hosts. Journal of Animal Ecology 57: 89-96. 2

Ray, C. \& Hastings, A. (1996). Density dependence: are we searching at the wrong spatial scale? Journal of Animal Ecology 65: 556-566. 3

Reineking, B. \& Schröder, B. (2004). Gütemaße für Habitatmodelle. In: Dormann, C. F., Blaschke, T., Lausch, A., Schröder, B. \& Söndgerath, D. (eds.) Habitatmodelle - Methodik, Anwendung, Nutzen, UFZ-Berichte 9/2004, pp. 27-37. 8

Romeis, J., Babendreier, D., Wäckers, F. \& Shanower, T. G. (2005). Habitat and plant specificity of Trichogramma egg parasitoids - underlying mechanisms and implications. Basic and Applied Ecology 6: 215-236. 2, 4, 15

Root, R. B. (1973). Organization of a plant-arthropod association in simple and diverse habitats: the fauna of collards (Brassica oleracea). Ecological Monographs 43: 95-124. 2, 14

Saunders, D. A., Hobbs, R. J. \& Margules, C. R. (1991). Biological consequences of ecosystem fragmentation: a review. Conservation Biology 5: 18-32. 14

Schmeil, O. \& Fitschen, J. (1996). Flora von Deutschland und angrenzender Länder. Quelle \& Meyer, Wiesbaden. 3

Schmidt, J. M. (1991). The role of physical factors in tritrophic interactions. Redia 74: 43-93. 3

Schröder, B. (2000). Zwischen Naturschutz und theoretischer Ökologie: Modelle zur Habitateignung und räumlichen Populationsdynamik für Heuschrecken im Niedermoor. Ph.D. thesis, University of Oldenburg. 8

Schröder, B. \& Reineking, B. (2004). Validierung von Habitatmodellen. In: Dormann, C. F., Blaschke, T., Lausch, A., Schröder, B. \& Söndgerath, D. (eds.) Habitatmodelle - Methodik, Anwendung, Nutzen, vol. 9/2004, UFZ-Berichte, vol. 9/2004, pp. 47-56. 8

Schwörer, U. \& Völkl, W. (2001). Foraging behavior of Aphidius ervi (Haliday) (Hymenoptera: Braconidae: Aphidiinae) at different spatial scales: resource utilization and suboptimal weather conditions. Biological Control 21: 111-119. 3

Solomon, B. P. (1981). Response of a host-specific herbivore to resource density, relative abundance, and phenology. Ecology 62: 1205-1214. 2, 14

Steffan-Dewenter, I., Münzenberg, U., Bürger, C., Thies, C. \& Tscharntke, T. (2002). Scale-dependent effects of landscape context on three pollinator guilds. Ecology 83: 1421-1432. 14

Stiefel, V., Nechols, J. R. \& Margolies, D. (1997). Development and survival of Anomoea flavokansiensis (Coleoptera: Chrysomelidae) as affected by temperature. Environmental Entomology 26: 223-228. 16 
Strong, D. R., Lawton, J. H. \& Southwood, T. R. E. (1984). Insects on Plants. Community Patterns and Mechanisms. Blackwell, London. 2

Thomas, J. A., Bourn, N. A. D., Clarke, R. T., Stewart, K. E., Simcox, D. J., Pearman, G. S., Curtis, R. \& Goodger, B. (2001). The quality and isolation of habitat patches both determine where butterflies persist in fragmented landscapes. Proceedings of the Royal Society B: Biological Sciences 268: 1791-1796. 14

Trautner, J., Geigenmüller, K. \& Bense, U. (1989). Käfer beobachten, bestimmen. Neumann-Neudamm, Melsungen. 3

Tscharntke, T. \& Brandl, R. (2004). Plant-insect interactions in fragmented landscapes. Annual Review of Entomology 49: 405-430. 3

Tscharntke, T., Steffan-Dewenter, I., Kruess, A. \& Thies, C. (2002). Characteristics of insect populations on habitat fragments: a mini review. Ecological Research 17: 229-239. 2, 14

Vidal, S. \& Tscharntke, T. (2001). Multitrophic plant-insect interactions. Basic and Applied Ecology 2: 1-2. 2, 14

Vinson, S. B. (1976). Host selection by insect parasitoids. Annual Review of Entomology 21: 109-133. 15

Vinson, S. B. (1991). Chemical signals used by parasitoids. Redia 74: 15-42. 3

White, T. C. R. (1993). The Inadequate Environment. Nitrogen and the Abundance of Animals. Springer, Berlin. 12

Wiens, J. A. (1989). Spatial scaling in ecology. Functional Ecology 3: 385-397. 3

Wilson, D. \& Faeth, S. H. (2001). Do fungal endophytes result in selection for leafminer ovipositional preference? Ecology 82: 1097-1111. 3

With, K. A. \& Crist, T. O. (1995). Critical thresholds in species' responses to landscape structure. Ecology 76: $2446-$ 2459. 14

Zweig, M. H. \& Campbell, G. (1993). Receiver-operating characteristic (ROC) plots: a fundamental tool in clinical medicine. Clinical Chemistry 39: 561-577. 8 